\title{
APPROPRIATE UTILIZATION OF QUALITY OF LIFE OUTCOMES IN PROSTATE AND BLADDER CANCER: PRACTICAL CONSIDERATIONS FOR BRAZILIAN PORTUGUESE QUESTIONNAIRES
}

\author{
doi: $10.1590 / \mathrm{S} 1807-59322009000500019$
}

Flavio L. Heldwein, ${ }^{\mathrm{I}, \mathrm{II}}$ Ernani L. Rhoden, ${ }^{\mathrm{I}}$ Antonio Hartmann, ${ }^{\mathrm{III}}$ Claudio Teloken ${ }^{\mathrm{I}}$

Quality of life (QOL) measurements have become an end-point that is as important as survival and effectiveness. ${ }^{1}$ More and more emphasis is being placed on QOL outcomes in urology, as evidenced by the development of minimally invasive procedures and the use of diaries and validated questionnaires in research and clinical practice. ${ }^{2}$

Health-related quality of life may incorporate a wide variety of subjective concepts, such as general health, physical symptoms, role functioning, and social wellbeing. Data generated by patient-reported outcome (PRO) instruments provide a means for measuring treatment benefits that are known only to the patient. ${ }^{3,4}$

The literature reveals that the most appropriate judge of individual QOL is the patient him- or herself. ${ }^{5}$ Different treatments may be associated with long-term complications that could adversely affect QOL.

In urological oncology, regardless of oncological safety, patients and their physicians make decisions based on quality of life issues, such as: sexual, bowel, and urinary function and bother.

Since February 2006, our research group has been working in cooperation with Dr. Mark Litwin (University of California - Los Angeles) in order to translate and validate a Portuguese version of the UCLA Prostate Cancer Index (UCLA-PCI). ${ }^{6}$ This questionnaire is a cross-culturally validated instrument that is available in many languages and

\footnotetext{
I Division of Urology, Department of Surgery, Universidade Federal de Ciências da Saúde de Porto Alegre - Porto Alegre/RS, Brazil.

II Division of Urology, Hospital Regional São José - Florianopolis/SC, Brazil.

III Department of Pathology, Universidade Federal de Ciências da Saúde de Porto Alegre - Porto Alegre/RS, Brazil.

Email: flavio.lobo@gmail.com

Tel.: 5548 3223.0816
}

is considered as the gold-standard for evaluation of QOL in prostate cancer patients. ${ }^{5}$

We have also been working on a project designed to develop the Brazilian bladder and prostate questionnaire modules with the European Organization for Research and Treatment of Cancer (EORTC) QOL Group (Dr. N Aaronson and Ms. Linda Dewolf). ${ }^{7}$ The EORTC PR25 (prostate), BLS24 (superficial bladder cancer), and BLM30 (muscleinvasive bladder cancer) questionnaires have been culturally adapted for the Brazilian context.

The use of cancer-specific modules has made standardization of results possible, thus minimizing the variability of concepts between medical specialties and between authors in different countries. ${ }^{4}$

Indeed, we anticipated several distress factors that can contribute to a lower response rate of our patients, including the low literacy level of the Brazilian population, the presence of words that require minimal technical knowledge, and the fact that patients are often unwilling to disclose private information, such as sexual matters, on paper, thus resulting in missing data.

The aim of this brief communication is to emphasize the importance of these questionnaires in our country when comparing urinary continence data from patient files registered by the attendant physician with the respective patient answers using a validated urinary incontinencespecific measure (International Consultation on Incontinence Questionnaire Short Form, ICIQ-SF). The PCI item regarding the number of pads or adult diapers was also applied.

Thirty medical files among the 210 patients included in the Brazilian UCLA-PCI project validation were randomly selected and reviewed.

With regard to continence status, the attendant correctly 
diagnosed only $40 \%$ (12/30) of the cases. Considering grades of urinary incontinence, the urologist was accurate only $44 \%(13 / 30)$ of the time. The number of pads registered differed between the medical file and the patient self-report in 20\% of the cases (6/30). Even when patients were considered as perfectly continent by the physician, $53 \%(8 / 15)$ of them reported that urinary incontinence interfered with their daily life. Even worse, seven patients diagnosed as continent by the physicians reported that urinary incontinence had a significant negative impact on their daily activities.

\section{TAKE-HOME MESSAGE}

Patient self-reports differ from health professional evaluations. Health professional registries tend to underestimate the severity of symptoms. The use of validated questionnaires is paramount in clinical studies.

The psychometric tests (i.e., reliability, validation) comprising of UCLA-PCI and EORTC PR25 have been performed, and the results of these tests will soon be presented. The EORTC bladder modules are still in Phase 3 of development. All four of the PRO questionnaires (UCLAPCI, EORTC PR25, BLS24, and BLM30) are now available for clinical trials in Brazil.

\section{REFERENCES}

1. Gill TM, Feinstein AR. A Critical-Appraisal Of The Quality Of QualityOf-Life Measurements. Jama-Journal Of The American Medical Association. 1994;272:619-26.

2. Rosen RC, Riley A, Wagner G, Osterloh IH, Kirkpatrick J, Mishra A. The international index of erectile function (IIEF): A multidimensional scale for assessment of erectile dysfunction. Urology. 1997;49:822-30.

3. Ware JE, Sherbourne CD. The Mos 36-Item Short-Form Health Survey (Sf-36).1. Conceptual-Framework And Item Selection. Med Care. 1992;30:473-83.

4. Guillemin F, Bombardier C, Beaton D. Cross-Cultural Adaptation Of Health-Related Quality-Of-Life Measures - Literature-Review And Proposed Guidelines. Journal Of Clinical Epidemiology. 1993;46:141732.
5. Litwin MS, Lubeck DP, Henning JM, Carroll PR. Differences in urologist and patient assessments of health related quality of life in men with prostate cancer: Results of the CaPSURE database. Journal Of Urology. 1998;159:1988-92.

6. Litwin MS, Hays RD, Fink A, Ganz PA, Leake B, Brook RH. The UCLA Prostate Cancer Index - Development, reliability, and validity of a health-related quality of life measure. Med Care. 1998;36:1002-12.

7. Aaronson NK, Ahmedzai S, Bergman B, Bullinger M, Cull A, Duez NJ, et al. The European-Organization-For-Research-And-Treatment-OfCancer Qlq-C30 - A Quality-Of-Life Instrument For Use In International Clinical-Trials In Oncology. J Natl Cancer Inst. 1993;85:365-76. 